\title{
What kinds of fish stock predictions do we need and what kinds of information will help us to make better predictions?*
}

\author{
KEITH BRANDER \\ ICES, Palaegade2-4, DK1261 Copenhagen K, Denmark. E-mail keith@ices.dk
}

\begin{abstract}
SUMMARY: Fish stock predictions are used to guide fisheries management, but stocks continue to be over-exploited. "Traditional" single-species age-structured stock assessment models, which became an operational component of fisheries management in the 1950s, ignore biological and environmental effects. As our knowledge of the marine environment improves and our concern about the state of the marine ecosystem and about global change increases, the scope of our models needs to be widened. We need different kinds of predictions as well as better predictions. Population characteristics (rates of mortality, growth, recruitment) of 61 stocks of 17 species of NE Atlantic fish are reviewed in order to consider the implications for the time-scale and quality of stock predictions. Short life expectancy limits the time horizon for predictability based on the current fishable stock and predictions are therefore more dependent on estimates or assumptions about future rates. Evidence is presented that rates of growth and recruitment are influenced by environmental factors and possibilities for including new information are explored in order to improve predictions.
\end{abstract}

Key words: fisheries management, population dynamics, stock assessment, fish stock prediction, Northeast Atlantic fisheries.

\section{INTRODUCTION}

The main purpose of fish stock predictions is to provide guidance on how to manage fisheries and their supporting ecosystems in a way which is sustainable. The kind of prediction which is required depends on the form of management. Management bodies, often referred to as the "customers" or "clients" for the advice, require annual updates of certain kinds of assessment, using particular models and specified quality standards throughout the assessment process. This routine (Fig. 1) is part of a regular institutional and statutory procedure in which the stock assessment is an operational component.

\footnotetext{
*Received December 6, 2000. Accepted July 7, 2001.
}

In the Northeast Atlantic the principal form of management is by annual Total Allowable Catches (TAC) for a number of species. The level of TAC is guided by "traditional" single species assessments, based mainly on age structured models. The data used in these models are estimates of the number, size and maturity of each age group in the commercial catch and the fishing effort used to take that catch. Research surveys are also used to provide information on the populations, particularly the numbers of "pre-recruit" fish, which are not represented in the commercial landings.

The purposes, procedures and data requirements for stock assessment and prediction are interdependent. Therefore the paper will take a broad view, which includes some of the history, operational con- 


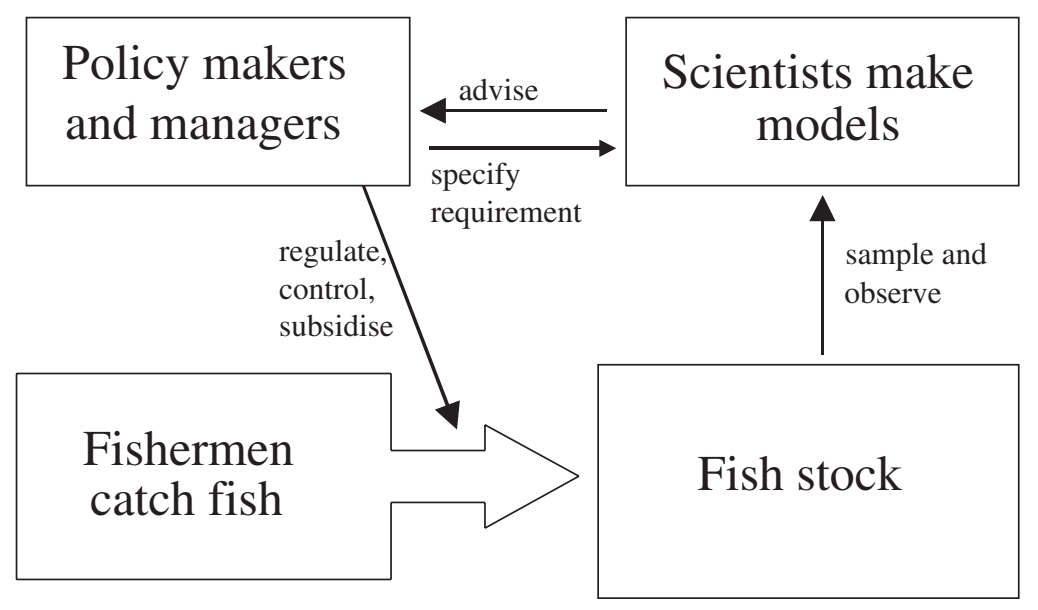

FIG. 1. - Diagram of the annual assessment and management procedure for regulating fisheries.

siderations and current drivers for change, in order to stimulate the debate on how future assessment and management might be carried out. Many other papers deal with improvements to current assessment methodology and go into detail about how environmental information may be used. I will say little about this aspect here.

For operational, management purposes the models used should be widely accepted and should not be subject to frequent change. This operational use of models is rather different from the function which they perform in science, where they are used to explore relationships, to explain observations in a consistent way and to clarify and communicate ideas. Science progresses by evaluating, changing and sometimes discarding models. In science there will often be several competing and possibly contradictory models relating to the same observations and system.

In the short term the frequency and kind of stock assessment to be carried out and the species to be included are mainly determined by fisheries managers, but this is not a one-way process. Over a longer time scale the purposes, form and procedures of fisheries management are influenced by changing scientific ideas about the marine ecosystem and how it may be exploited in a sustainable way. The current form and procedures for fisheries management have their roots in the single species age structured modelling pioneered fifty years ago by Beverton, Holt, Gulland and many others. A comment by Michael Graham, director of the Lowestoft Laboratory where these three worked, during discussion of a paper presented by Gulland (1962) provides an insight into this operationalisation, which followed directly from the school of operational research pioneered during the Second World War:
"The historical background (to the equation described by Gulland) is an interesting one. It was produced not by zoologists becoming devotees of mathematics, but because they were forced by policy to look for a more or less rigid equation useful as a guide to factors of first and second magnitude, and as a basis for advice to the Government which was engaging in international negotiations. It was also of value in defining the kind of data which needed to be obtained by such things as marking experiments, to give critical information about important parameters."

Fisheries management has come to rely to heavily on the form of management which derives from the "traditional" mathematical formalism, but the limitations, which were always recognised by the pioneers, have perhaps not been adequately allowed for. A more critical approach is now evident. For example, Schnute and Richards (2001) say: "In the 1990's mathematical models suffered a declining reputation as tools for fishery management. The collapse of various important fish stocks demonstrated that quantitative stock assessment methods provide no guarantee that a fishery will remain sustainable." This seems a little unfair; even the Ten Commandments provide no guarantee against sin.

Fisheries management can be viewed as a feedback control system (Fig. 1) and it is evident that in many cases the failures of fisheries management have more to do with problems of how to regulate catching activity than with shortcomings in the scientific advice. However even if this is true, it does not absolve the role of science, for at least two reasons. First, as argued above, the current form and procedures of fisheries management have been 
heavily influenced by the prevailing scientific world view. Second, science can and should have a reflexive role in evaluating the outcome of the management process. A role for ACFM ( the Advisory Committee on Fisheries Management of ICES) in reviewing and commenting on management proposals was put forward at the time of its founding (Brander, 1978), but has not been implemented. In this context it is arguable that the prominent role played by biological models may have resulted in neglect of the insights provided by other sciences, such as economics or control theory. It may be time to redress the balance

"Traditional" fisheries models and assessments have played a valuable role in fisheries management and should continue to do so, but changing circumstances provide compelling reasons for developing additional or alternative models, with different time scales, resolution and processes, which include other scientific disciplines.

\section{Drivers for change}

Reasons for developing new kinds of assessment and prediction can be classified as negative or positive, i.e. criticisms of existing methodology or reasons for expecting future improvements. Negative drivers include:

- Dissatisfaction with the existing procedures, because of the failure of fisheries management to curb high levels of fishing. Papers by (Cochrane, 2000) and (Schnute and Richards, 2001) articulate many of the surrounding issues.

- Concern that "traditional" assessments do not provide useful guidance or predictions on mediumand long-term changes, which affect issues such as long-term stock recovery, distribution changes, species replacement and biological variability.

- Concern about assessing the potential impacts of climate change scenarios, which "traditional" models are not designed for.

- Concern about the state of the marine environment, which means that it is no longer acceptable to attempt to manage only a few commercial species without considering the impact on other parts of the system. A recent article by (Wallstrom, 2000), EU Environmental Commissioner, expresses this policy change and its consequences: "What still lies ahead of us is the arduous exercise of defining environmental objectives for the fisheries sector together with a system of indicators for the future monitoring of policy performance, and the adoption of a long- term strategy and legal instruments to achieve policy objectives." Rather like the earlier quote from Michael Graham, we see the demand for regular institutional and statutory procedures leading to the operationalisation of assessments and models, perhaps before they are ready to bear such a burden. The danger with operationalising a system prematurely is that one may foreclose superior alternatives. The institutional and statutory procedures should therefore be kept open to change until it is reasonably clear that the adopted methodology will be adequate for the task.

Positive drivers include:

- Rapid improvement in our routine observation, sampling, monitoring and modeling of the marine environment. This increased flow of information can lead to major improvements in our ability to understand and manage fisheries, but the procedures for interpreting and applying the information need to be developed.

- Information about past variability in fish stocks and the way in which this was influenced by environmental change.

- Improved understanding of the processes which govern fish stock fluctuations.

Against this background, the remainder of the paper will describe and compare some of the characteristics of current and past exploited fish populations (life expectancy, growth, recruitment) in order to consider the implications for the time-scale and quality of predictions. For example, common patterns of variability of population characteristics between stocks (at interannual or longer time scales) may point to common causes acting at scales bigger than the individual stock.

\section{POPULATION CHARACTERISTICS}

"Traditional" fisheries models are based on estimates of characteristic population processes (growth, maturity, fecundity, mortality and recruitment) for each stock. The effect of fishing is assessed and a management regime (usually an annual TAC) is established. Stock boundaries are not always clear-cut. For example, large areas, such as the North Sea, may contain a number of substocks, which differ in their population characteristics and could be regarded as separable units. Conversely, exchanges often occur across the boundaries of stocks which are nominally separate and it is not uncommon for stock boundaries to be adjusted. 
TABLE 1. - Population characteristics

\begin{tabular}{|c|c|c|c|c|c|c|c|c|c|c|}
\hline Species & $\begin{array}{r}\text { Life e } \\
=1\end{array}$ & $\begin{array}{l}\text { expectancy } \\
\text { (years) } \\
1 /(\mathrm{F}+\mathrm{M})\end{array}$ & $\begin{array}{l}\text { Natural } \\
\text { mortality } \\
\text { (M) }\end{array}$ & $\begin{array}{l}\text { Age span } \\
\quad \text { for } \\
\text { average } F\end{array}$ & $\begin{array}{c}\mathrm{CV} \text { of } \\
\text { spawning } \\
\text { biomass }\end{array}$ & $\begin{array}{l}\mathrm{CV} \text { of } \\
\text { recruits }\end{array}$ & $\begin{array}{l}\text { Age of } \\
\text { recruits }\end{array}$ & $\begin{array}{l}\text { Auto- } \\
\text { correlation } \\
\text { of recruits } \\
\text { lag } 1 \mathrm{yr}\end{array}$ & $\begin{array}{l}\text { Growth rate } \\
\text { of mature } \\
\text { fish }\left(\mathrm{yr}^{-1}\right)\end{array}$ & $\begin{array}{l}\text { Years } \\
\text { of data }\end{array}$ \\
\hline Anchovy & Biscay & 0.53 & 1.2 & $1-3$ & 38 & 53 & 0 & & & 14 \\
\hline Angler (=Monk) & Celtic Sea \& Biscay & 2.43 & 0.15 & $6-10$ & 38 & 29 & 2 & & & 30 \\
\hline Blue whiting & ICES area & 2.04 & 0.2 & $3-7$ & 26 & 68 & 0 & & & 20 \\
\hline Cod & $\begin{array}{l}\text { Baltic E } \\
\text { Baltic W } \\
\text { Celtic Sea } \\
\text { Faroe } \\
\text { Iceland } \\
\text { Irish Sea } \\
\text { Kattegat only } \\
\text { N. Sea } \\
\text { NE Arctic } \\
\text { Norwegian coastal } \\
\text { W. Scotland }\end{array}$ & $\begin{array}{l}0.96 \\
0.77 \\
1.12 \\
1.54 \\
1.32 \\
0.94 \\
0.84 \\
1.05 \\
1.28 \\
1.83 \\
1.04\end{array}$ & $\begin{array}{l}0.2 \\
0.2 \\
0.2 \\
0.2 \\
0.2 \\
0.2 \\
0.2 \\
0.22 \\
0.2 \\
0.2 \\
0.2\end{array}$ & $\begin{array}{l}4-7 \\
3-6 \\
2-5 \\
3-7 \\
5-10 \\
2-4 \\
3-5 \\
2-8 \\
5-10 \\
4-7 \\
2-5\end{array}$ & $\begin{array}{l}61 \\
35 \\
37 \\
37 \\
56 \\
40 \\
57 \\
46 \\
79 \\
22 \\
48\end{array}$ & $\begin{array}{l}61 \\
58 \\
75 \\
56 \\
\mathbf{3 9} \\
60 \\
\mathbf{5 5} \\
61 \\
\mathbf{6 2} \\
47 \\
60\end{array}$ & $\begin{array}{l}2 \\
1 \\
1 \\
2 \\
3 \\
0 \\
1 \\
1 \\
3 \\
2 \\
1\end{array}$ & $\begin{array}{l}\mathbf{0 . 7 8} \\
0.32 \\
0.30 \\
0.31 \\
0.18 \\
0.09 \\
0.33 \\
0.10 \\
\mathbf{0 . 4 7} \\
0.51 \\
0.01\end{array}$ & $\begin{array}{l}0.45 \\
0.49 \\
0.40 \\
0.31 \\
0.25 \\
0.36 \\
\\
0.35 \\
0.26 \\
\\
0.62\end{array}$ & $\begin{array}{l}35 \\
31 \\
30 \\
40 \\
46 \\
33 \\
30 \\
38 \\
55 \\
16 \\
35\end{array}$ \\
\hline Common sole & $\begin{array}{l}\text { Biscay } \\
\text { Celtic Sea } \\
\text { E.English Channel } \\
\text { Irish Sea } \\
\text { Kattegat \& Skagerrak } \\
\text { N. Sea } \\
\text { W.English Channel }\end{array}$ & $\begin{array}{l}1.94 \\
1.98 \\
2.02 \\
1.95 \\
\mathrm{k} 2.28 \\
2.19 \\
2.61\end{array}$ & $\begin{array}{l}0.1 \\
0.1 \\
0.1 \\
0.1 \\
0.1 \\
0.1 \\
0.1\end{array}$ & $\begin{array}{l}2-6 \\
4-8 \\
3-8 \\
4-7 \\
4-8 \\
2-8 \\
3-7\end{array}$ & $\begin{array}{l}10 \\
34 \\
15 \\
23 \\
42 \\
52 \\
31\end{array}$ & $\begin{array}{l}16 \\
\mathbf{3 3} \\
38 \\
68 \\
46 \\
93 \\
40\end{array}$ & $\begin{array}{l}1 \\
1 \\
1 \\
2 \\
2 \\
1 \\
1\end{array}$ & $\begin{array}{r}0.44 \\
-0.05 \\
-0.04 \\
0.23 \\
\mathbf{0 . 6 0} \\
-0.14 \\
0.31\end{array}$ & $\begin{array}{l}0.29 \\
0.26 \\
0.20 \\
0.18 \\
0.21 \\
0.16\end{array}$ & $\begin{array}{l}17 \\
30 \\
19 \\
31 \\
17 \\
44 \\
32\end{array}$ \\
\hline Flounder & Baltic C & 1.39 & 0.2 & $4-6$ & 22 & 26 & 2 & & & 29 \\
\hline G. halibut & NE Arctic & 2.33 & 0.15 & $6-10$ & 62 & 59 & 5 & & & 36 \\
\hline Haddock & $\begin{array}{l}\text { Faroe } \\
\text { Iceland } \\
\text { Irish Sea } \\
\text { N. Sea } \\
\text { NE Arctic } \\
\text { Rockall } \\
\text { W. Scotland }\end{array}$ & $\begin{array}{l}2.08 \\
1.27 \\
0.73 \\
0.86 \\
1.41 \\
1.41 \\
1.18\end{array}$ & $\begin{array}{l}0.2 \\
0.2 \\
0.2 \\
0.26 \\
0.2 \\
0.2 \\
0.2\end{array}$ & $\begin{array}{l}3-7 \\
4-7 \\
2-4 \\
2-6 \\
4-7 \\
2-5 \\
2-6\end{array}$ & $\begin{array}{l}36 \\
25 \\
61 \\
71 \\
42 \\
41 \\
59\end{array}$ & $\begin{array}{r}82 \\
73 \\
90 \\
148 \\
124 \\
78 \\
127\end{array}$ & $\begin{array}{l}2 \\
2 \\
0 \\
0 \\
3 \\
1 \\
1\end{array}$ & $\begin{array}{r}0.37 \\
0.10 \\
-0.73 \\
0.03 \\
0.04 \\
0.04 \\
-0.15\end{array}$ & $\begin{array}{l}0.22 \\
\\
0.33 \\
0.19 \\
0.19 \\
0.35\end{array}$ & $\begin{array}{r}40 \\
22 \\
8 \\
38 \\
51 \\
16 \\
36\end{array}$ \\
\hline Hake & $\begin{array}{l}\text { Northern } \\
\text { Southern }\end{array}$ & $\begin{array}{l}2.05 \\
1.70\end{array}$ & $\begin{array}{l}0.2 \\
0.2\end{array}$ & $\begin{array}{l}2-6 \\
2-5\end{array}$ & $\begin{array}{l}24 \\
37\end{array}$ & $\begin{array}{l}35 \\
\mathbf{3 0}\end{array}$ & $\begin{array}{l}0 \\
1\end{array}$ & $\begin{array}{l}0.55 \\
0.72\end{array}$ & 0.34 & $\begin{array}{l}23 \\
19\end{array}$ \\
\hline Herring & $\begin{array}{l}\text { Baltic E } \\
\text { Celtic Sea } \\
\text { Gulf of Bothnia N } \\
\text { Gulf of Bothnia S } \\
\text { Iceland } \\
\text { Irish Sea } \\
\text { N. Sea } \\
\text { Norwegian spring sp. } \\
\text { W. Ireland }\end{array}$ & $\begin{array}{l}1.96 \\
1.75 \\
2.11 \\
2.92 \\
2.61 \\
2.08 \\
1.58 \\
3.53 \\
2.52\end{array}$ & $\begin{array}{l}0.22 \\
0.11 \\
0.15 \\
0.15 \\
0.1 \\
0.12 \\
0.16 \\
0.15 \\
0.11\end{array}$ & $\begin{array}{l}3-6 \\
2-7 \\
3-7 \\
3-7 \\
4-14 \\
2-6 \\
2-6 \\
5-14 \\
3-6\end{array}$ & $\begin{array}{c}36 \\
35 \\
37 \\
36 \\
67 \\
43 \\
80 \\
101 \\
45\end{array}$ & $\begin{array}{r}33 \\
53 \\
73 \\
46 \\
75 \\
55 \\
\mathbf{6 4} \\
165 \\
67\end{array}$ & $\begin{array}{l}1 \\
1 \\
0 \\
1 \\
1 \\
1 \\
0 \\
0 \\
1\end{array}$ & $\begin{array}{l}0.31 \\
0.09 \\
0.09 \\
0.35 \\
\mathbf{0 . 4 5} \\
\mathbf{0 . 5 3} \\
\mathbf{0 . 4 4} \\
0.27 \\
0.02\end{array}$ & $\begin{array}{l}0.25 \\
0.18\end{array}$ & $\begin{array}{l}27 \\
43 \\
20 \\
21 \\
54 \\
29 \\
41 \\
51 \\
31\end{array}$ \\
\hline Horse mackerel & Southern & 2.86 & 0.15 & $1-11$ & 18 & 36 & 0 & & 0.17 & 16 \\
\hline Mackerel & $\begin{array}{l}\text { NE Atlantic } \\
\text { Western }\end{array}$ & $\begin{array}{l}2.76 \\
2.88\end{array}$ & $\begin{array}{l}0.15 \\
0.15\end{array}$ & $\begin{array}{l}4-8 \\
4-8\end{array}$ & $\begin{array}{l}14 \\
12\end{array}$ & $\begin{array}{l}24 \\
37\end{array}$ & $\begin{array}{l}0 \\
0\end{array}$ & $\begin{array}{r}0.08 \\
-0.12\end{array}$ & 0.21 & $\begin{array}{l}17 \\
28\end{array}$ \\
\hline Megrim & $\begin{array}{l}\text { Celtic Sea \& Biscay } \\
\text { Iberia }\end{array}$ & $\begin{array}{l}2.05 \\
1.94\end{array}$ & $\begin{array}{l}0.2 \\
0.2\end{array}$ & $\begin{array}{l}3-6 \\
2-4\end{array}$ & $\begin{array}{l}17 \\
58\end{array}$ & $\begin{array}{l}14 \\
70\end{array}$ & $\begin{array}{l}1 \\
1\end{array}$ & & & $\begin{array}{l}16 \\
29\end{array}$ \\
\hline Plaice & $\begin{array}{l}\text { Celtic Sea } \\
\text { E.English Channel } \\
\text { Irish Sea } \\
\text { Kattegat \& Skagerrak } \\
\text { N. Sea } \\
\text { W.English Channel }\end{array}$ & $\begin{array}{l}1.38 \\
1.56 \\
1.52 \\
\mathrm{k} 1.17 \\
2.33 \\
1.53\end{array}$ & $\begin{array}{l}0.12 \\
0.1 \\
0.12 \\
0.1 \\
0.1 \\
0.1\end{array}$ & $\begin{array}{l}3-6 \\
2-6 \\
3-6 \\
4-8 \\
2-10 \\
3-7\end{array}$ & $\begin{array}{l}34 \\
27 \\
33 \\
23 \\
21 \\
35\end{array}$ & $\begin{array}{l}50 \\
40 \\
38 \\
33 \\
49 \\
53\end{array}$ & $\begin{array}{l}1 \\
1 \\
1 \\
2 \\
1 \\
1\end{array}$ & $\begin{array}{l}\mathbf{0 . 5 8} \\
0.24 \\
\mathbf{0 . 4 8} \\
0.42 \\
0.18 \\
\mathbf{0 . 5 8}\end{array}$ & $\begin{array}{l}0.23 \\
0.23 \\
0.28 \\
0.19 \\
0.22\end{array}$ & $\begin{array}{l}24 \\
21 \\
37 \\
23 \\
44 \\
25\end{array}$ \\
\hline Saithe & $\begin{array}{l}\text { Faroe } \\
\text { Iceland } \\
\text { N. Sea } \\
\text { NE Arctic }\end{array}$ & $\begin{array}{l}2.05 \\
1.92 \\
1.42 \\
1.74\end{array}$ & $\begin{array}{l}0.2 \\
0.2 \\
0.2 \\
0.2\end{array}$ & $\begin{array}{l}4-8 \\
5-12 \\
3-6 \\
3-6\end{array}$ & $\begin{array}{l}24 \\
45 \\
57 \\
58\end{array}$ & $\begin{array}{l}49 \\
58 \\
\mathbf{5 4} \\
\mathbf{4 5}\end{array}$ & $\begin{array}{l}3 \\
3 \\
1 \\
2\end{array}$ & $\begin{array}{l}\mathbf{0 . 4 1} \\
\mathbf{0 . 6 3} \\
0.25 \\
0.13\end{array}$ & $\begin{array}{l}0.22 \\
0.19 \\
0.29 \\
0.29\end{array}$ & $\begin{array}{l}40 \\
39 \\
29 \\
41\end{array}$ \\
\hline Sprat & Baltic & 1.94 & 0.23 & $3-5$ & 64 & 83 & 1 & 0.09 & & 27 \\
\hline Whiting & $\begin{array}{l}\text { Celtic Sea } \\
\text { Irish Sea } \\
\text { N. Sea } \\
\text { W. Scotland }\end{array}$ & $\begin{array}{l}1.01 \\
0.89 \\
0.86 \\
1.02\end{array}$ & $\begin{array}{l}0.2 \\
0.2 \\
0.32 \\
0.2\end{array}$ & $\begin{array}{l}2-5 \\
1-3 \\
2-6 \\
2-4\end{array}$ & $\begin{array}{l}56 \\
57 \\
37 \\
44\end{array}$ & $\begin{array}{l}48 \\
46 \\
60 \\
53\end{array}$ & $\begin{array}{l}0 \\
0 \\
1 \\
1\end{array}$ & $\begin{array}{r}\mathbf{0 . 5 6} \\
0.03 \\
0.37 \\
-0.02\end{array}$ & $\begin{array}{l}0.34 \\
0.46 \\
0.31 \\
0.27\end{array}$ & $\begin{array}{l}19 \\
21 \\
41 \\
23\end{array}$ \\
\hline
\end{tabular}


Table 1 shows some of the population characteristics of 61 stocks of 17 species from the annual stock assessments which are carried out by ICES Working Groups for the NE Atlantic (ICES, 2001). The "data" are in fact mainly model output from the Virtual Population Analyses (VPA), which are used to reconstruct population characteristics. Details of the methodology used for sampling and population analysis differ somewhat from stock to stock and can be found in the relevant Working Group reports.

\section{Life expectancy}

The average life expectancy or "half life" is given by the probability that a fish will be alive at some future time $\mathrm{T}$ and is the inverse of the average total instantaneous mortality $(\mathrm{Z})$, since:

$$
\int_{T=0}^{T=\infty} \exp -(Z T)=\left[\frac{\exp -(Z T)}{Z}\right]_{0}^{\infty}=\frac{1}{Z}
$$

where $\mathrm{Z}=$ Fishing mortality $(\mathrm{F})+$ Natural mortality $(\mathrm{M})$ (This is also known as the $e$-folding scale)

$\mathrm{F}$ is averaged over an "adult" age span (shown in Table 1), chosen by the group which carried out the assessment.

The life expectancy of fish in the ICES area, once they are subject to the "adult" total mortality, is rather short, being highest for Norwegian spring spawning herring, horse mackerel and mackerel (3.53, 2.9 and 2.8 years respectively) and lowest for anchovy, Irish Sea haddock and western Baltic cod $(0.53,0.73$ and 0.77 years respectively). The life expectancy of gadoid stocks is less than two years from when they enter the fishable stock, with the exception of Faroe haddock and saithe (2.08, 2.05 years) and blue whiting (2.04 years), but life expectancy for most of the flatfish and pelagic stocks is greater than two years. Short life expectancy limits the time horizon for prediction based on the inventory or "virtual population" of fish currently in the fishable stock, but does not necessarily entail vulnerability. For example, the life expectancy of a typical teleost egg is a few days, whereas that of an elasmobranch is much longer, but this has little bearing on the resilience or vulnerability of their respective life histories. Figure 2a shows life expectancies of four stocks. The other panels of the Figure have the same time scale and are used to relate life expectancy and stock prediction. $\mathbf{a}$
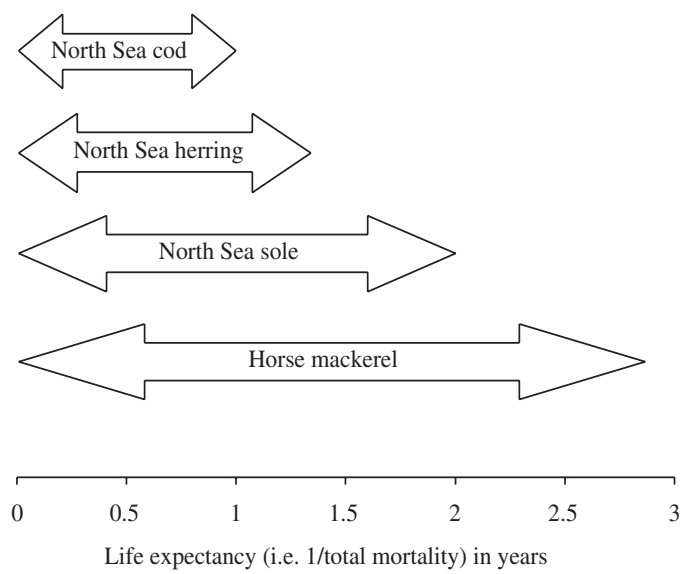

b
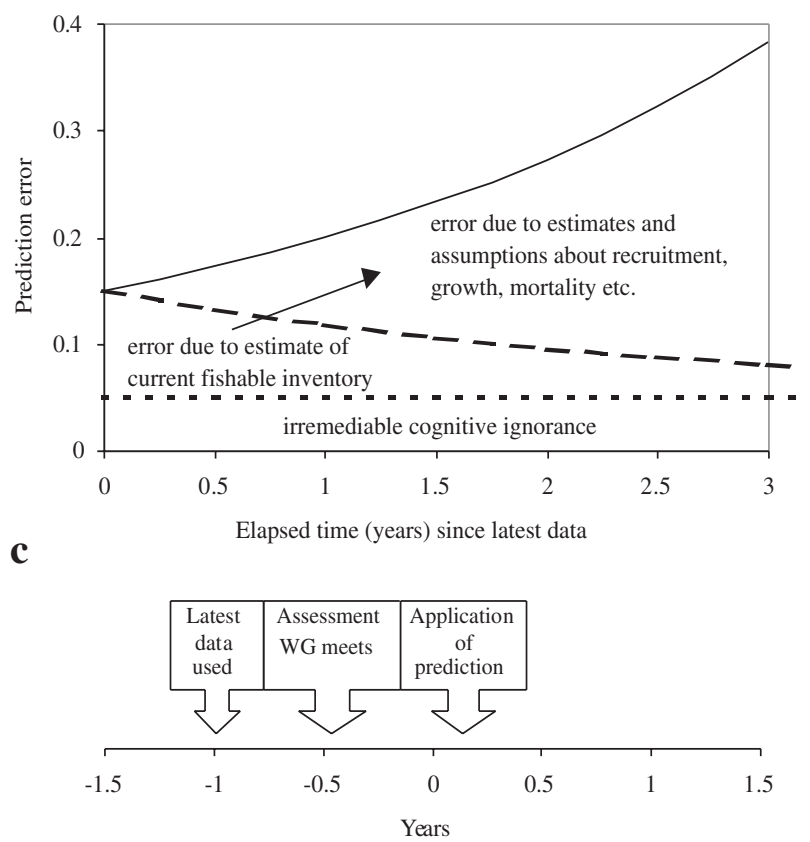

FIG. 2. - a) Life expectancy of four North Sea stocks (horse mackerel has a wider distribution than the North Sea); b) Diagram showing how the components of the prediction error change as the elapsed time since the most recent data became available increases; c) Schematic representation of the time of data availability, time of the scientific assessment and time of the management decison. Time zero on the $\mathrm{x}$-axis is the beginning of the year to which the management advice applies. The scale is roughly the current situation in EU waters. Note that the time scale is the same for all three parts of Fig 2.

\section{Growth rates}

The growth rate of mature fish in Table 1 is the weighted annual instantaneous rate for fish of ages which are more than $50 \%$ mature. Mortality and growth rates are in comparable units (i.e. year ${ }^{-1}$ ). Since growth rate is primarily a function of the size of fish, much of the variation in growth rate shown in Table 1 is due to variation in the size at maturity between stocks. For example, $50 \%$ of Baltic cod mature at about $0.7 \mathrm{~kg}$, but North Sea cod do not 
TABLE 2. - Correlations between recruit numbers (upper right triangle) and adjusted numbers of degrees of freedom (lower left triangle). Bold numbers indicate $\mathrm{p}<0.01$

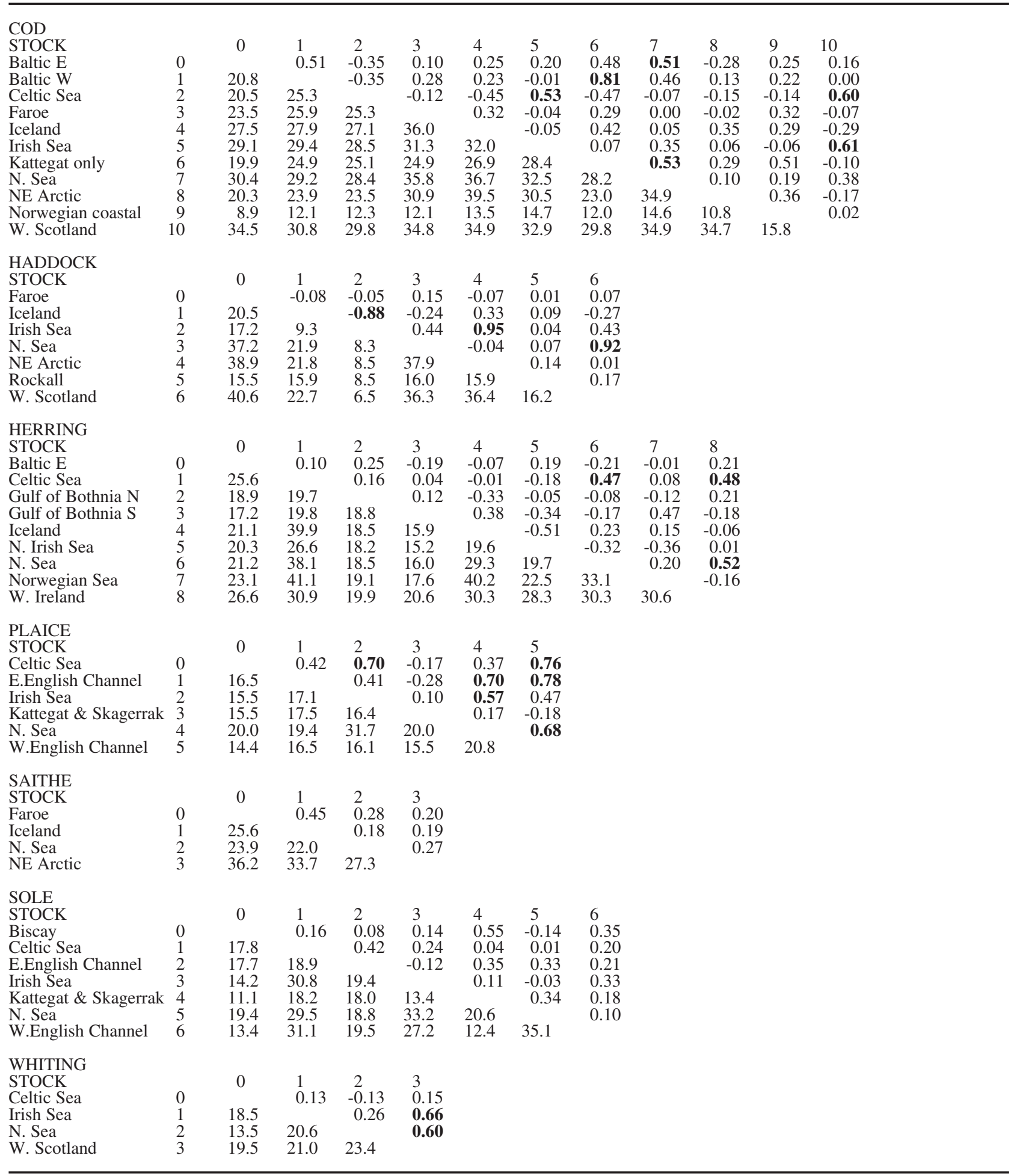

reach this point until they weigh over $3 \mathrm{~kg}$. Therefore, although North Sea cod grow faster than Baltic cod over the entire weight range, the growth rate of the average mature (small) cod in the Baltic is greater than in the North Sea.

\section{Recruitment}

The coefficients of variation $(\mathrm{CV})$ of recruits (i.e. number of fish in a yearclass) and spawning stock biomass are given in Table 1, together with 


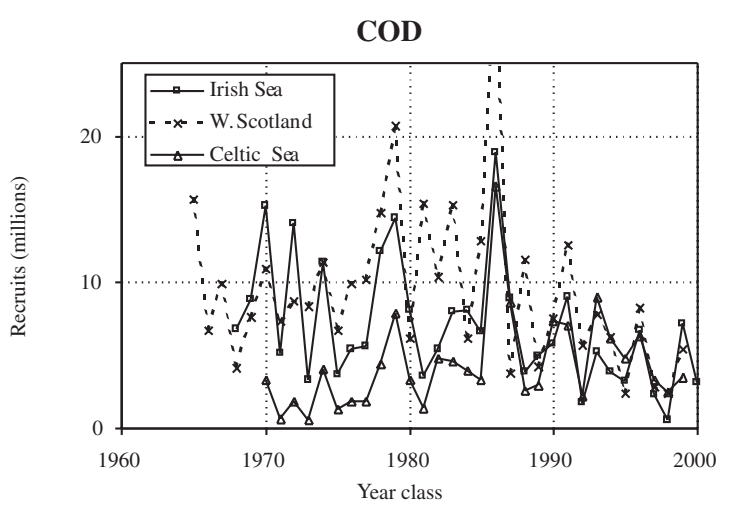

HERRING

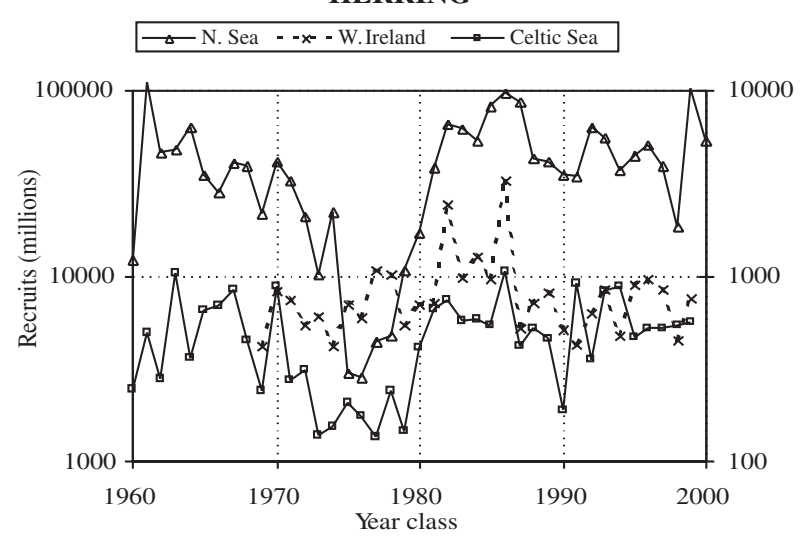

PLAICE

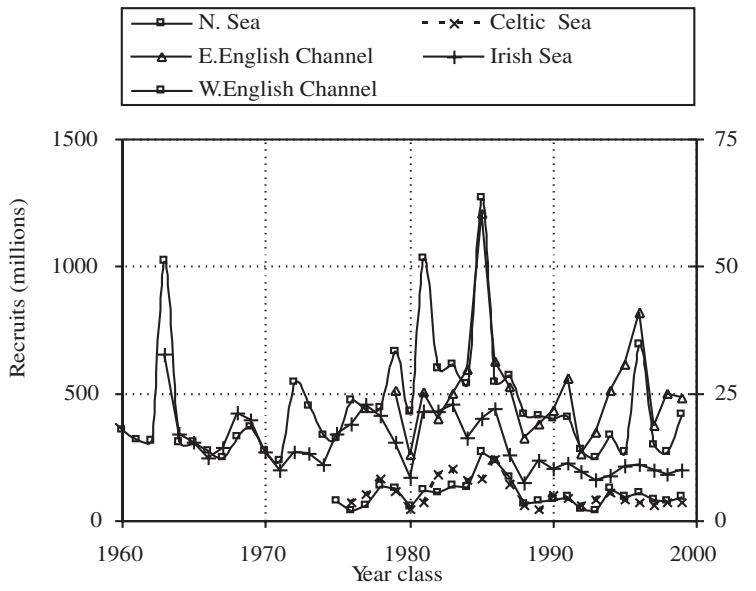

FIG. 3. - Time series of recruitment for cod, herring and plaice stocks around the British Isles. The correlation coefficients between these time series are given in Table 2.

the age of the recruits and the autocorrelation of recruits at 1 year lag. The $\mathrm{CV}$ of recruitment is in bold where it is less than the CV of biomass. The autocorrelation coefficients are in bold where they are significant at the $1 \%$ level. Recruitment of stocks of seven of the species shown in the table have been correlated against each other, in order to explore synchronous patterns of variability. The method recommended by (Pyper and Peterman,
1998) was used to adjust the number of degrees of freedom to take account of autocorrelation and their recommended estimator of the correlation coefficient $r$ (modified Box-Jenkins method) was also adopted. Adjusted degrees of freedom are shown in Table 2 and $r$ values are given in bold where they are significant at the $1 \%$ level. Recruitment time series of stocks around the British Isles, which show synchronicity, are plotted in Figure 3.

\section{Age composition of the landings}

The contribution of different ages to the landed weight of each stock is shown in Figure 4. Thus, in the North Sea and Irish Sea about 50\% of the landed weight of cod consists of 1 and 2 year old fish, whereas at Faroe the proportion of 2year-olds is only $10 \%$. In the North Sea, Irish Sea, Celtic Sea, West of Scotland and Western Baltic the recruiting year class of cod is one year old, but in every case the one-year-olds make up less than $10 \%$ of the landings on average. At Faroe and in the Eastern Baltic the recruiting year class is two years old and at Iceland and in the NE Arctic they are three years old.

\section{DISCUSSION}

\section{Life expectancy and short term stock prediction}

How long is a short term prediction? For a phytoplankton population (algal bloom) a few days or weeks might be considered appropriate, whereas for a whale population the time span might be several orders of magnitude greater. For fish the period 1-3 years is often used, but this definition derives from management considerations and does not take account of the population characteristics of the species and stock in question. A definition which relates the time span to the nature of the prediction is that the period of a short term assessment is equal to the life expectancy (shown in Table 1). Leaving aside the effects of growth (which causes biomass to disappear from the stock more slowly than numbers) and assuming a steady state, this is the point when the recruited and non-recruited fractions of the population are equal.

"Traditional" assessment models deal mainly with the recruited fraction and are principally designed to provide short term predictions, based on an age structured inventory of fish alive now (main- 


\section{Cod}

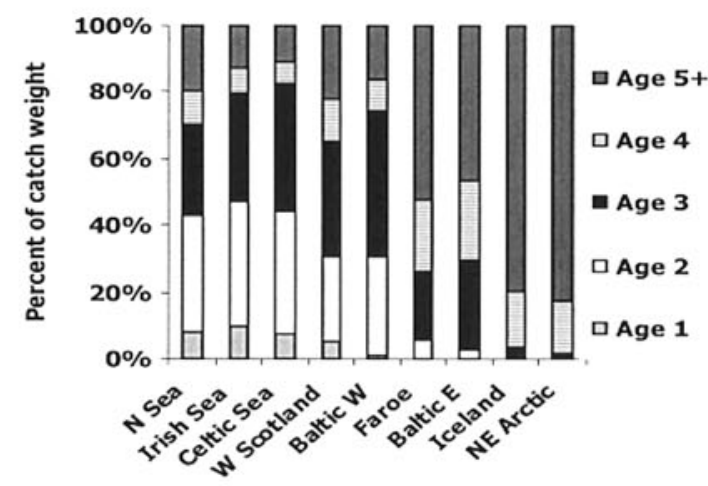

Haddock

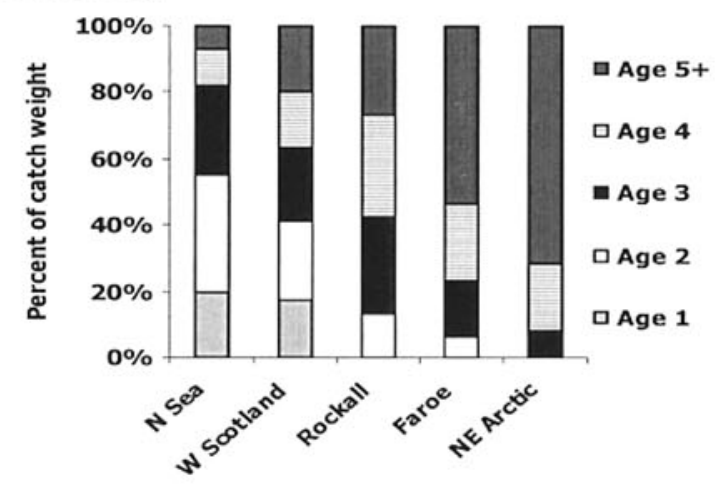

Whiting

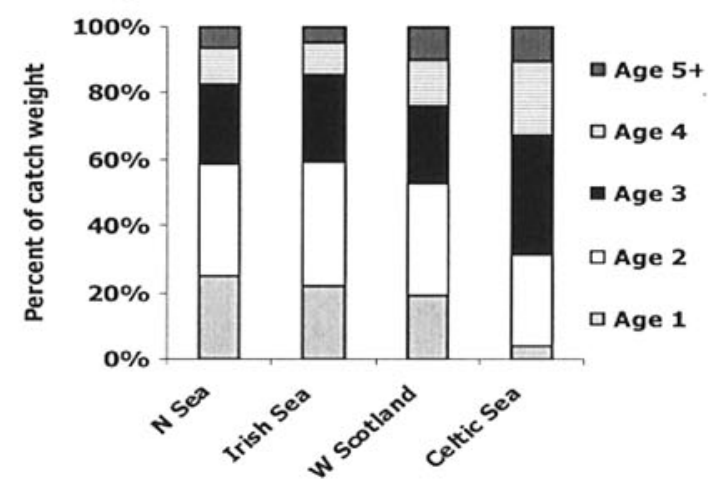

Herring

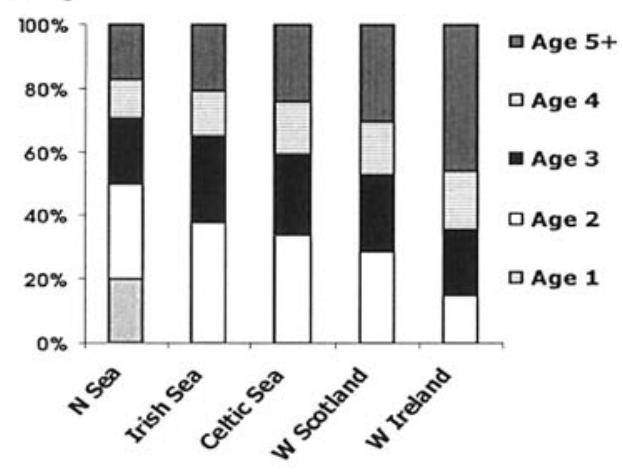

Saithe

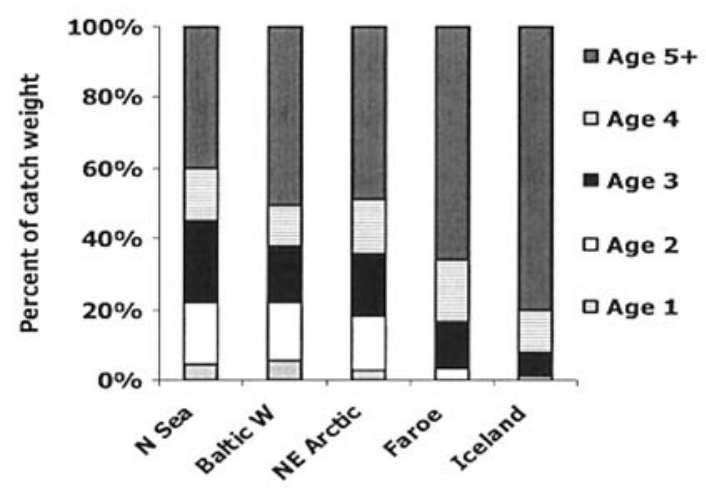

Plaice

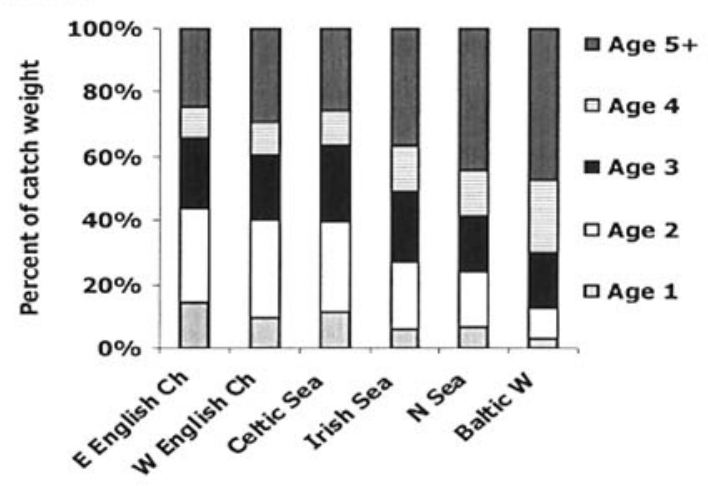

Sole

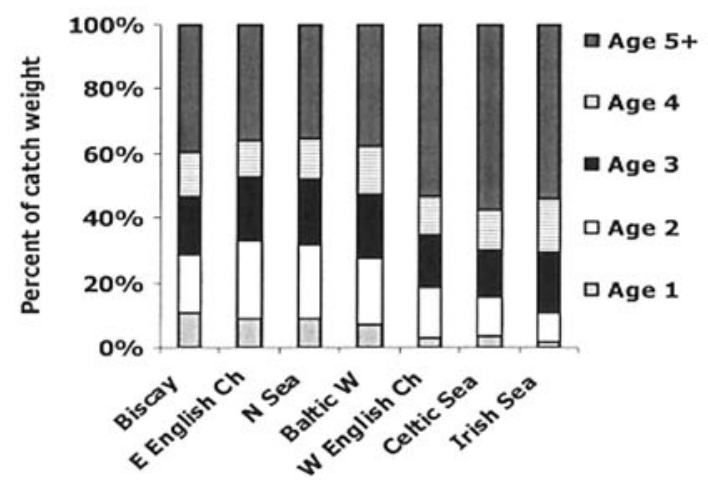

Other species

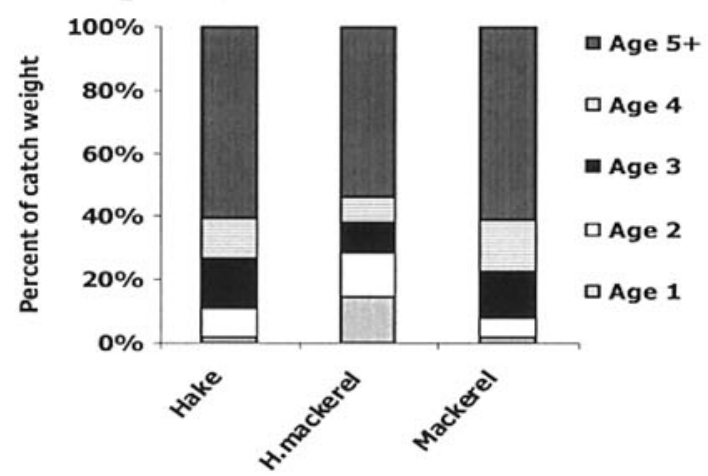

FIG. 4. - Percentage contributed by each age group to the total landed weight of 44 stocks of 10 species in the ICES assessment area. The most recent yearclass included is 1997 . The number of years varies between stocks and is given in Table 1 
ly based on virtual population analysis). In the short term, the effects of estimates and assumptions about future rates of recruitment and growth are small, but the balance tips when predicting the medium and long term.

The detailed biological book-keeping, using the age-structured inventory for short term prediction, is made possible by the fact that individual fish can be aged from their otoliths. This is quantitatively satisfying, but has diverted much effort in fisheries science away from the uncertain assumptions, which dominate the medium and long term and from the need to understand the underlying causes of variability in fish distribution and population parameters, including growth, fecundity, maturity, survival, recruitment and biological interactions with the rest of the marine ecosystem.

A schematic representation of the way in which prediction error changes with time (Fig. 2b) brings out some of the issues concerning the utility of different kinds of information. The prediction error can be divided into a (lower) part which will always be there (labelled "irremediable cognitive ignorance") and an upper part which may in turn be divided into remediable cognitive ignorance and voluntative ignorance (i.e. we don't know how human decisions may affect the prediction). In the schematic the upper part of the prediction error is divided into the "recruited" and "non-recruited" fractions of the population. The former is labelled "error due to estimate of current fishable inventory" and is shown declining at a rate roughly equivalent to the life expectancy of North Sea cod (i.e. 50\% gone after one year). The arrow connecting the two upper areas of the prediction error is intended to indicate that the boundary between them is porous, i.e. information about the current stock helps to estimate future recruitment, growth etc.

The bottom panel of Figure 2 shows roughly the current time-scale for making a stock prediction and applying it in EU waters. At the time when a prediction is applied, the data used to make the prediction is about one year old. This is the same as the period of a short term prediction for a stock like North Sea cod (life expectancy 1 year), as defined above, therefore one could say that the predictions used to manage North Sea cod are medium term (i.e. based mainly on the non-recruited part of the stock). The prediction error can be reduced by increasing the life expectancy (i.e. reducing fishing mortality), using more up-to-date data in the prediction and applying the prediction more rapidly.

\section{Predicting variability in growth}

In principle it should be much easier to predict variability in growth than in recruitment. Growth rate can be measured relatively easily for individual fish and populations. The factors governing growth are well known. For example, we know from theory (Brett, 1979), experiments and field studies that temperature governs rate processes and has a major influence on fish growth. Many other factors also have an effect, including genetics, food, light and activity level, but if inter-annual variability in growth rate is the main concern in relation to fish stock prediction, then there are strong reasons for dealing with temperature first. We have good data on interannual variability in temperature, whereas interannual variability in other factors is either nil (genetics), small (light, activity level) or difficult to measure (available food). However before considering the predictability of growth, it is worth evaluating whether variability in growth affects stock predictions sufficiently to be worth spending time on.

Figure 5 shows the prediction error for the North Sea and NE Arctic cod stocks which is due to interannual variability in growth. The prediction uses the correct numbers at age (i.e. those estimated in later years by VPA) and the most recent data on weights at age, so the error arises because recent weight at age is not always a good predictor of future weight at age. For North Sea cod the predictions are within $12 \%$ of the observed biomass, but the errors for NE Arctic cod are up to $36 \%$, so improved prediction of weight at age could reduce prediction error substantially in some cases.

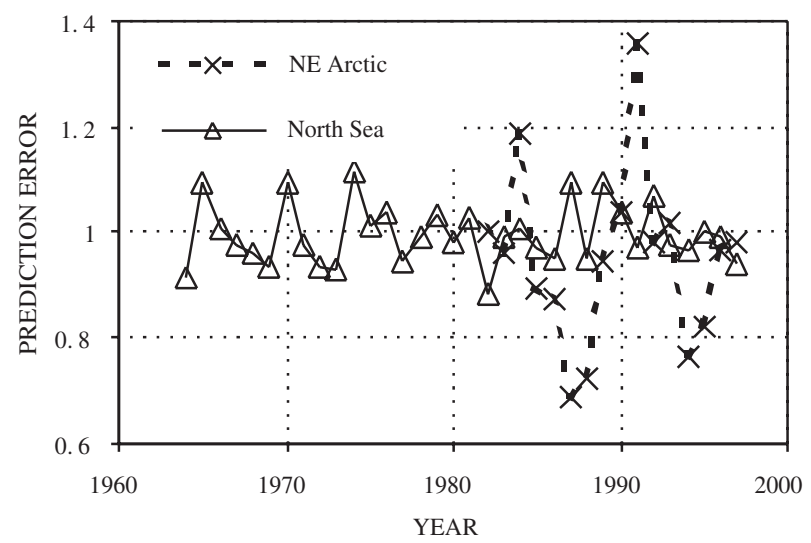

FIG. 5. - Contribution of interannual variability in growth to the error in predicting stock biomass 1-year-ahead (predicted/actual) for North Sea and NE Arctic cod. The error is due to the assumption that weight-at-age remains unchanged from the most recent value at the time of the assessment. 


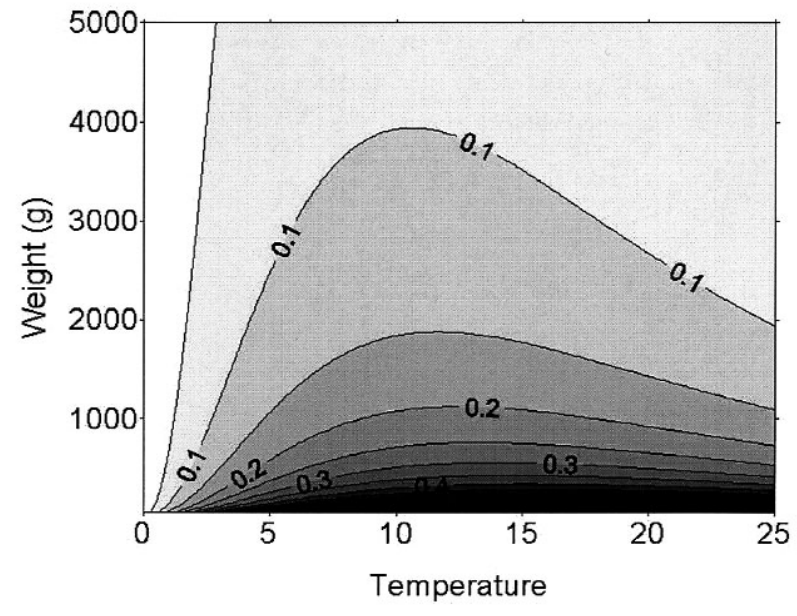

FIG. 6. - Daily specific growth rate of cod $\left[\ln \left(\right.\right.$ weight $_{t+1} /$ weight $\left.\left._{t}\right) * 100\right]$ $=0.83 *$ temperature $*$ Weight $\left(-0.0114^{*}\right.$ temperature -0.42$)$. This is close to, but not the same as growth rate expressed as \% per day. The parameters are fitted using weight at age data for the cod stocks listed in Table 1.

Whether temperature (or other environmental information) can in practice improve prediction of weight at age depends on two principal issues:

- Can ambient temperature be defined, measured and possibly predicted in a timely way, with sufficient accuracy?

- Can an adequate (not necessarily complete) model of growth be constructed?

Experience with experiments and aquaculture suggests that these issues are not simple, but are tractable. A recently developed model of growth rates of cod (Fig. 6) (ICES, 2000), illustrates the non-linear effect of temperature and the decline in specific growth rate and optimal temperature with size. The implications of this model are that temperature variability has a much greater effect in early life, and that this is when much of the variability in size at age may be generated. For NE Arctic cod it seems that the weight at 4-5 months can vary by a factor of 3, depending on the ambient temperature during their first months of life (Loeng et al., 1995; Ottersen and Loeng, 2000). For North Sea cod the temperature during the first year of life appears to account for $26 \%$ of the subsequent variability in weight at age 3 (Brander, 2000).

The large changes in weight at age for NE Arctic cod during the period 1982-1991 were clearly also related to the availability of food, specifically capelin, so in this case a model which only included temperature would clearly be inadequate. However, the effect of capelin on condition and growth of NE Arctic cod is only apparent when the biomass of capelin drops below 1 million tonnes
(Yaragina and Marshall, 2000), which is quite an extreme situation.

If a substantial fraction of the variability in weight at age can be predicted from temperature during early life, then this suggests that such information could result in a useful reduction in prediction errors, without requiring predictions of future temperature. On the other hand, one might ask why a more direct approach could not be used, in which young fish were surveyed during their first year and the estimate of their size used as a predictor of subsequent size at older ages? One reason for using temperature is that young fish surveys are expensive, whereas temperature data are usually freely obtainable. If young fish surveys are already taking place in order to estimate abundance, then the marginal cost of estimating size is small, but even in this case, temperature data may provide additional information. If the survey design, fishing method or gear are size-selective, then size at age may be inadequately estimated. In this case an estimate of size at age derived from temperature may be more precise and may even contribute to an improved estimate of abundance in the surveys, by allowing for a correction which takes the interannual variability in size into account.

The argument put forward here is that current temperature data may reduce errors in predicting weight at age, but information about future temperature would clearly also be valuable. All stock forecasts require a prediction of future weight at age, whether this is explicit or not. If there is a strong expectation that temperature in future will not be the same as in the past then the "status quo ante" assumption for weight at age may not be very sensible.

\section{Recruitment variability and population processes}

Fishermen have known for centuries that annual recruitment of fish is highly variable. Their livelihood depends on a supply of fish which may fluctuate greatly from year to year or over longer time scales (particularly if they are dependent on one species, such as salmon). The resultant variability in stock and catches also causes problems for fisheries management. However, from a biologist's perspective, when considering the population dynamics of species whose progeny are reduced in number by five or six orders of magnitude before they recruit, it is astonishing how little recruitment varies. Research on recruitment should investigate the 
processes which limit the variability as well as those which generate it (Amara et al., 2000; Rijnsdorp et al., 1992; Van der Veer, 1986)

With the exception of haddock and North Sea sole, the coefficient of variation $(\mathrm{CV})$ of recruitment is between 15 and $64 \%$. For fourteen of the sixtyone stocks included in Table 1 the $\mathrm{CV}$ of recruitment is less than the CV of stock biomass. Furthermore, many of the recruitment time series show evidence of low frequency variability and are strongly autocorrelated, so the CV is an inadequate statistic for scaling the variability. Recruitment of the three principal pelagic species in the ICES area is no more variable than that of most demersal stocks and considerably less variable than some.

\section{Estimating recruitment using pre-recruit surveys}

The balance between recruited and non-recruited fractions in the future stock has been discussed above. The non-recruited fraction (i.e. those too small to appear in the commercial landings) can be estimated from research surveys, using fine mesh nets. If the young fish do not enter the fishery until they are several years old (e.g. NE Arctic cod see Figure 4), then this provides a long period over which the size of a yearclass can be estimated. Annual research surveys are often used to obtain accurate (but expensive) estimates of incoming year classes. Unless recruitment can be adequately estimated using other (cheaper) data, then annual research surveys must be regarded as "perpetual short-term indicators", i.e. they have to be repeated in perpetuity. Note that such surveys are not predicting the number of fish in a year class, but are estimating it prior to recruitment, with the assumption that the mortality during the intervening period is constant. It is not obvious that annual recruitment surveys result in better understanding of the processes causing variability of recruitment.

\section{Short-term variability in recruitment and environmental factors}

Even when annual pre-recruit surveys give a reasonable estimate, data on environmental conditions (e.g. temperature) may give additional information about yearclass strength, but three conditions need to be satisfied: the effect should be significant; there should be a credible explanation of the process by which the environmental factor acts; and the envi- ronmental information must be available in a timely and cost-effective form. Concerning the first of these, the effect of adding environmental information will not be significant if the contribution of that age group to the prediction is small (e.g. any of the age groups contributing less than $10 \%$ in Fig. 4). Concerning the second, credible explanation of processes is fundamental to scientific progress. The identification of processes permits more precise definition and measurement of the appropriate environmental variable and a clearer understanding of the circumstances in which such a prediction may or may not work (because other factors come into play). Concerning the third, availability of timely and appropriate environmental data at an acceptable cost is clearly essential and there are encouraging signs that such operational oceanographic products are becoming routine.

In a review entitled "Is Research on Environmental Factors Useful to Fisheries Management?" (Walters and Collie, 1988) concluded that "Improved prediction is often impossible in principle because environmental factors are not predictable even if fish responses are. In some fisheries, prediction could be achieved more cheaply and reliably by direct monitoring programs, such as prerecruitment surveys of year-class strengths." The time frame for this comparison seems misleading. If a prerecruit survey gives a reliable estimate of subsequent year-class strength, then the influence of environmental (or other factors) has already taken place and could therefore presumably be measured. If the environmental (or other) factors act after the prerecruit survey, then the estimate from the survey will not be reliable.

The assertion that environmental factors are not predictable is also debatable; views on this are changing and although it remains true that detailed prediction of weather has a short time horizon, an immense scientific effort is now going into modelling likely future climate scenarios. Fisheries scientists have to judge whether to assume "status quo", i.e. that the future environment (as it affects recruitment in this instance) will be like the time period which generated the past recruitment record, or whether a directional change in environmental patterns is taking place. In the light of the observed changes in ocean climate since 1985 and the scenarios being developed by the IPCC, the "status quo" assumption seems a poor basis for medium- and-long term fisheries management strategies. 


\section{Long-term, large-scale variability in recruitment and the marine ecosystem}

Synchronicity of change in abundance (or recruitment) has been used as evidence of common external forcing of the dynamics of different taxa (Aebischer et al. 1990) and of geographically separated stocks and species (Klyashtorin, 1998; Downton and Miller, 1998). In an analysis of synchronicity of recruitment of North Atlantic cod stocks, (Myers et al., 1995) concluded that interannual anomalies in environmental variables could be imposing coherence and estimated a de-correlation (e-folding) scale of about $340 \mathrm{~km}$. Subsequently Myers et al. (1997) extended the analysis to include other species. The results presented in the present paper include more years, but are broadly comparable, though some differences in method and common findings require comment.

(Myers et al., 1995) carry out their analysis on $\ln$ (recruitment)/ln(spawning biomass), a "standardised" index of survival which might be expected to be sensitive to environmental factors. Myers et al. (1997) used the same methodology but also carried out an analysis in which the effect of spawner biomass was not removed . Recent work (Marshall et $a l ., 1998)$ indicates that the relationship between spawning biomass estimated from VPA and reproductive output is poor and that when interannual changes in fecundity and maturity are taken into account, the index of survival may look very different. Since changes in fecundity are never included and changes in maturity are treated erratically, if at all, the standardisation using spawning biomass may simply introduce more noise. An example which may illustrate this is the correlation between cod recruitment in the Kattegat and Eastern Baltic. These are adjacent sea areas, with dispersal and migration taking place between them, so one would expect their recruitment to vary synchronously, as it does ( $\mathrm{r}=0.81$; adjusted d.f. 24.9; $\mathrm{p}<0.01$; see Table $2)$. The value of $r$ using the log transformed recruitment is almost identical, but for $\ln$ (recruitment)/ $\ln$ (spawning biomass) it drops to 0.42 , which is almost identical to the value given by (Myers et al., 1995) (0.44) for a shorter period of years. The reason why the latter correlation is lower is because the maturity data for the two stocks is infrequently adjusted. If, as seems probable, environmental factors significantly affect fecundity, maturity and hence recruitment, then the processes and time span subject to environmental influence should be widened to include maturation and gonad production during the year leading up to spawning.

Table 2 shows which species, stocks and areas vary synchronously in the NE Atlantic. Twenty out of 160 correlations in the Table have a probability of $<0.01$. Only one of these twenty (haddock, Iceland * Irish Sea) is a negative correlation. All eight comparisons of recruitment of Icelandic stocks (cod, haddock and herring) with stocks of the same species west of the British Isles (Celtic Sea, Irish Sea, W of Scotland, W of Ireland) are negative. Inverse relationships are also characteristic of plankton (Planque and Fromentin, 1996), sea surface temperature and global radiance (Cayan, 1992) between Iceland and West of Britain. There are coherent, large scale system properties, driven by physical factors, which may be related to the NAO (North Atlantic Oscillation) with probable consequences for fisheries production. The time scale and indicators (e.g. biomass limits) used for management of fisheries and of the marine ecosystems should take these into account, but there is some way to go in determining how to do so.

\section{CONCLUSIONS}

Sustainable management of fisheries and of the ecosystems on which they depend requires a broader understanding of the effects of fishing than is provided by existing "traditional" stock assessments. Beyond the short term, which at current levels of fishing is generally less than two years, the variability of fish stocks is heavily dependent on factors which are not included in "traditional" models.

The evidence that environmental factors cause long-term, large-scale (sometimes synchronous) variability in fish stocks is growing, but it is a mistake to conclude that the effects of fishing are therefore less important. Because of the complexity of the processes governing recruitment, it may be difficult to improve short term predictions, but in the medium and long term, environmental information and scenarios for climate change should be included instead of assuming that the status quo will continue. The processes governing growth are simpler and environmental information may help to improve predictions, even at short time scales. Procedures which provide the appropriate environmental information in a timely and cost-effective way should be set up.

The goals, targets, indicators and methods for managing fisheries and marine ecosystems are like- 
ly to continue to develop for quite a long time. Setting up a rigid system of assessment and statute inevitably results in resistance to change and improvement, as is arguably now the case with fisheries. Given the complexity of the system, including its ecological, economic, social and political aspects, in a context of global change, a flexible and reflexive management process seems essential.

\section{ACKNOWLEDGEMENTS}

This work was funded by the US National Science Foundation Grant OCE-0075263, the UK Ministry of Agriculture Fisheries and Food Project MF0424, the Norwegian Research Council Project 13744/120, the Canadian Department of Fisheries and Oceans, the Icelandic Ministry of Fisheries and the EU Concerted Action FAIR-CT97-3805. It was also supported by the International Council for the Exploration of the Sea. I would like to express my gratitude to colleagues who took part in the SAP project.

\section{REFERENCES}

Aebischer, N.J., J.C. Coulson and J.M. Colebrook. - 1990. Parallel long-term trends across four marine trophic levels and weather. Nature, 347: 753-755.

Amara, R.F., Lagardere, Y. Desaunay and J. Marchand. - 2000. Metamorphosis and estuarine colonisation in the common sole, Solea solea (L.): implications for recruitment regulation. Oceanol. Acta, 23: 469-484.

Brander, K. - 1978. The effect of 200 mile limits on fisheries management in the Northeast Atlantic. FAO Fisheries Tech. Paper 183: $1-19$.

Brander, K. - 2000. Effects of environmental variability on growth and recruitment in cod (Gadus morhua) using a comparative approach. Oceanol. Acta, 23: 485-496.

Brett, J.R. - 1979. Environmental factors and growth. In: W.S.Hoar, D.J.Randall and J.R.Brett (eds.), Fish physiology. pp. 599-675. Academic Press, New York

Cayan, D.R. - 1992. Latent and sensible heat flux anomalies over the oceans: Driving the sea surface temperature. J. Phys. Oceanogr., 22: 859-881.
Cochrane, K.L. - 2000. Reconciling sustainability, economic efficiency and equity in fisheries: the one that got away? Fish and Fisheries 1: 3-21.

Downton, M.W. and K.A. Miller - 1998. Relationship between Alaskan salmon catch and North Pacific climate on interannual and interdecadal time scales. Can. J. Fish. Aquat. Sci., 55: $2255-2265$.

Gulland J.A. - 1962. The application of mathematical models to fish populations. In E.D. Le Cren and M.W. Holdgate (eds.), The Exploitation of Natural Animal Populations, pp. 204-220. Blackwell, Oxford.

ICES. - 2000. ICES/GLOBEC Workshop on the Dynamics of Growth in Cod. CM 2000/C:12, 114 .

ICES. - 2001. Report of the ICES Advisory Committee on Fishery Management, 2000. ICES Cooperative Res. Rep., 242.

Klyashtorin L.B. - 1998. Long-term climate change and main commercial fish production in the Atlantic and Pacific. Fisheries Res., 37: 115-125.

Loeng, H., H. Bjoerke and G. Ottersen. - 1995. Larval fish growth in the Barents Sea. In: Climate change and northern fish populations, pp. 691-698. National Research Council of Canada, Ottawa, ON-Canada.

Marshall,C.T., O.S. Kjesbu, N.A. Yaragina, P. Solemdal and O. Ulltang. - 1998. Is spawner biomass a sensitive measure of the reproductive and recruiment potential of Northeast Arctic cod? Can. J. Fish. Aquat. Sci., 55: 1766-1783.

Myers, R.A., G. Mertz and N. Barrowman - 1995. Spatial scales of variability in cod recruitment in the North Atlantic. Can. J. Fish. Aquat. Sci. 52: 1849-1862.

Ottersen, G. and H. Loeng. - 2000. Covariability in early growth and year-class strength of Barents Sea cod, haddock and herring: the environmental link. ICES J. Mar. Sci., 57: 339-348.

Planque, B. and J.-M. Fromentin. - 1996. Calanus and environment in the eastern North Atlantic. I.Spatial and temporal patterns of C. finmarchicus and C. helgolandicus. Mar. Ecol. Prog. Ser., 134: 101-109.

Pyper B.J. and R.M. Peterman. - 1998. Comparison of methods to account for autocorrelation in correlation analyses of fish data. Can. J. Fish. Aquat. Sci. 55: 2127-2140.

Rijnsdorp, A.D., F.A. Van Beek, S. Flatman, R.M. Millner, J.D. Riley, M. Giret and R. De Clerck. - 1992. Recruitment of sole stocks, Solea solea (L.) in the northeast Atlantic. Neth. J. sea. Res., 29: 173-192.

Schnute, J.T and L.J. Richards. - 2001. Use and abuse of fishery models. Can. J. Fish. Aquat. Sci., 58: 1-8.

Van der Veer. - 1986. Immigration, settlement and density-dependent mortality of a larval and early post-larval o-group plaice (Pleuronectes platessa) population in the western Wadden Sea. Mar. Ecol. Prog. Ser., 29: 223-236.

Wallstrom, M. - 2000. Fisheries: a case for more sustainable development. El Anzuelo 6.

Walters, C.J. and J.S. Collie. - 1988. Is research on environmental factors useful to fisheries management? Can. J. Fish. Aquat. Sci., 45: 1848-1854.

Yaragina, N.A. and C.T. Marshall. - 2000. Trophic influences on interannual and seasonal variation in the liver condition index of Northeast Arctic cod (Gadus morhua). ICES J. Mar. Sci., 57: 42-55. 